\title{
Thermal Storage Capacity and Night Ventilation Performance of a Solar Chimney Combined with Different PCMs
}

\author{
Jun Lu, Xiaolong Gao, Qianru Li, and Yongcai Li \\ Key Laboratory of the Three Gorges Reservoir Region's Eco-Environment, Ministry of Education, Chongqing University, \\ Chongqing, China \\ Correspondence should be addressed to Yongcai Li; yongcail85@163.com
}

Received 8 February 2017; Revised 5 April 2017; Accepted 22 May 2017; Published 5 July 2017

Academic Editor: Alibakhsh Kasaeian

Copyright ( 2017 Jun Lu et al. This is an open access article distributed under the Creative Commons Attribution License, which permits unrestricted use, distribution, and reproduction in any medium, provided the original work is properly cited.

\begin{abstract}
Thermal storage capacity and airflow rate of a solar chimney combined with different PCMs are numerically studied during nighttime. PCMs with phase change temperatures of $38^{\circ} \mathrm{C}, 44^{\circ} \mathrm{C}, 50^{\circ} \mathrm{C}$, and $63^{\circ} \mathrm{C}$ are selected in this numerical study. Results show that the maximum average ventilation rate of $610 \mathrm{~kg} / \mathrm{m}^{2}$ and maximum thermal storage of $4750 \mathrm{~kJ} / \mathrm{m}^{2}$ are achieved at the phase change temperature of $38^{\circ} \mathrm{C}$. However, for phase change temperature of $63^{\circ} \mathrm{C}$, night ventilation does not occur under the identical conditions. The findings reveal that a lower phase change temperature can increase the chargeability (and therefore the dischargeability) of a solar chimney, since a higher phase change temperature demands higher solar radiation intensity and longer charging time for a solar chimney. For PCM with a phase change temperature of $44^{\circ} \mathrm{C}$, most of the heat stored in PCM is lost to ambient through glass cover by radiation and only a small portion is used for heating the air within air channel.
\end{abstract}

\section{Introduction}

A solar chimney is a natural draft system that has already been applied in the building ventilation widely and has attracted the interest of many scholars around the world. Extensive numerical or/and experimental studies in terms of evaluating ventilation performance [1-5] and optimizing design of solar chimney [6-10] have been performed. A solar chimney consisted of roof solar collector, and Trombe wall was experimentally investigated by Khedari et al. [11]. Results show that in June July of a hot and humid climate, the temperature, air velocity, and flow rate per area of a solar chimney inside the room varies from $35-37^{\circ} \mathrm{C}$, $0.02-0.08 \mathrm{~m} / \mathrm{s}$, and $0.01-0.02 \mathrm{~m}^{3} / \mathrm{s}$ per $1 \mathrm{~m}^{2}$, respectively. Hirunlabh et al. [12] performed a numerical study on four new configurations of roof solar collector under Thailand weather conditions. By using the new configuration of roof solar collector, the highest volume flow rate of air is $0.072 \mathrm{~m}^{3} / \mathrm{s}$ or $0.0206 \mathrm{~m}^{3} / \mathrm{s}$ per $1 \mathrm{~m}^{2}$ of a solar chimney. Chungloo and Limmeechokchai found that with a solar chimney, the indoor temperature can be reduced by $1.0-$ $3.5^{\circ} \mathrm{C}$ at high ambient temperature and high solar intensity $\left(32.0-40.01^{\circ} \mathrm{C}\right)$ in the daytime [13]. Miyazaki et al. [14] numerically investigated the effects of solar chimneys on thermal load mitigation of office buildings in Japan. The results showed that in the natural ventilation mode, a larger chimney area was required to reduce the passive cooling load of the building. Between $10 \mathrm{a} . \mathrm{m}$. and 12 p.m. of an average day in May, when the chimney width is $4 \mathrm{~m}$, the cooling load was less than that of the no solar chimney design.

Studies reveal that the height [6], chimney position [7], type of absorber [8], width and depth of cavity [15], inclination angle [16], and the insulation or thermal mass in the solar chimney [17] are the primary factors that should be considered when designing a solar chimney. The above analysis indicated that solar chimney possesses the potential of cooling effect and cooling load reduction, and the potential can be enhanced by optimizing the designing factors. The available studies mainly concentrated on the performance characteristics of solar chimney during the daytime. If the night ventilation or all-day ventilation can be achieved, the solar energy utilization as well as the indoor thermal comfort would be greatly improved. Amori and Mohammed [18] 
experimentally investigated the effect of integrating phase change material (PCM) in a solar chimney and found that integrating a solar chimney with PCM yield longer ventilation period after the sunset. In this paper, a PCM unit is integrated into the solar absorber of the chimney to take advantage of PCM's isothermal phase change characteristic as well as high latent heat density. The PCM absorbs the heat radiated from the sun and stores heat during the daytime and then releases the absorbed heat during the nighttime. By this means, night ventilation can be achieved without consuming any additional energy sources. This has been indicated by Liu and Li's study [19], in which the performance of a conventional vertical solar chimney and a PCM-based one with the same geometry was compared. In their study, the paraffin wax with phase change temperature of $38-42^{\circ} \mathrm{C}$ was selected as PCM. It was found that the effective ventilation time of the PCM-based solar chimney can be as long as $13 \mathrm{~h} 50 \mathrm{~min}$, while the conventional one' ventilation time is only $1 \mathrm{~h}$ 20 min. Similarly, Zhou and Pang [20] experimentally studied the thermal behavior of a system with a collectorstorage wall using PCM with phase change temperature $26 \pm 1^{\circ} \mathrm{C}$. The experimental results indicated that by integrating PCM in the wall, the whole ventilation period of the system is as long as $17.5 \mathrm{~h}$.

It is should be noticed that the PCM can significantly influence the ventilation performance of the PCM-based solar chimney, especially the phase change temperature of the PCM, which is a vital factor among the physical properties of the PCM. It directly affects the absorber temperature and consequently affects the air flow rate and thermal storage capacity.

Based on the findings from above literatures, a mathematical model is developed to examine the ventilation performance and thermal storage capacity of a solar chimney using different PCMs under hot summer climatic conditions. The results of this paper could help to enhance the performance of such a PCM-based solar chimney by optimizing the phase change temperature.

\section{Description of Mathematical Model}

The schematic diagram of the PCM-based solar chimney is shown in Figures 1 and 2. The system mainly consists of glazing cover, air cavity, heat absorber plate, PCM container, and extruded insulation panels.

2.1. Calculation of the Energy Stored during the Day. The inlet and outlet of this system are closed when PCM is storing the solar energy during the day. Solar radiation passes through the glazing cover and is absorbed by the absorber. Then, the absorbed energy is used to raise the temperature of PCM. When the PCM temperature reaches its phase change temperature, the PCM starts to melt and stores latent heat simultaneously. During this period, the temperature of the PCM remains relatively constant.

Applying the energy balance concept on the glazing cover and the absorber plate, the following equations are given:

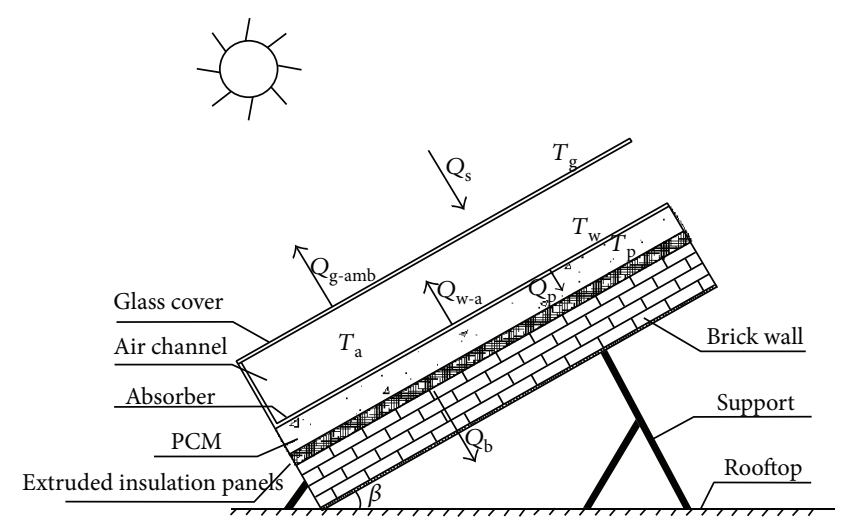

FIgURE 1: Schematic diagram of the PCM-based solar chimney during daytime.

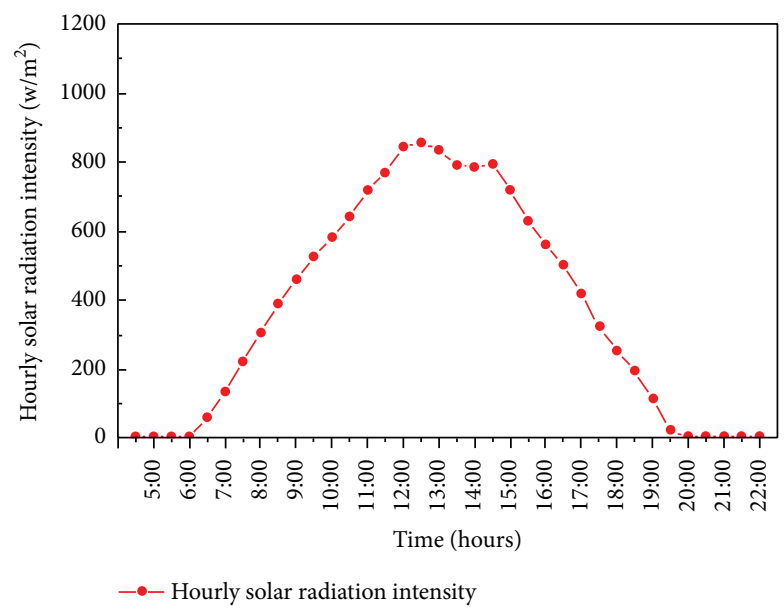

FIgURE 2: Hourly solar radiation intensity for June 26, 2016, in Chongqing, China [27].

$$
\begin{gathered}
\rho_{\mathrm{g}} C_{\mathrm{g}} \delta_{\mathrm{g}} A_{\mathrm{g}} \frac{d T_{\mathrm{g}}}{d t}=\alpha_{\mathrm{g}} q_{\mathrm{s}} A_{\mathrm{g}}+h_{\mathrm{r}, \mathrm{w}-\mathrm{g}}\left(T_{\mathrm{w}}-T_{\mathrm{g}}\right) A_{\mathrm{w}}-U_{\mathrm{t}}\left(T_{\mathrm{g}}-T_{\mathrm{amb}}\right) A_{\mathrm{g}}, \\
\rho_{\mathrm{w}} C_{\mathrm{w}} \delta_{\mathrm{w}} A_{\mathrm{w}} \frac{d T_{\mathrm{w}}}{d t}=\tau_{\mathrm{g}} \alpha_{\mathrm{w}} q_{\mathrm{s}} A_{\mathrm{w}}-h_{\mathrm{r}, \mathrm{w}-\mathrm{g}}\left(T_{\mathrm{w}}-T_{\mathrm{g}}\right) A_{\mathrm{w}}-h_{\mathrm{w}-\mathrm{p}}\left(T_{\mathrm{w}}-T_{\mathrm{p}}\right) A_{\mathrm{w}} .
\end{gathered}
$$

Theoretically, the glass receives heat from solar radiation and radiative heat from the absorber plate while it loses energy to ambient. The absorber plate, made by a thin stainless steel with high thermal conductivity, is used to absorb solar energy. Hence, it is reasonably assumed that there is no thermal gradient across the thickness of the absorber plate. Consequently, the absorber plate absorbs solar radiation through the glass cover while releases heat to the glass cover and the PCM.

In this paper, the PCM is sealed in a metallic container, which is assumed to be in good thermal contact with the PCM. And the absorber plate serves as a heat exchanger between the air and the container. Hence, the control volume method for discrete one-dimensional phase change problems is adopted. The PCM container is divided into $n(n=10)$ cells 
along the thickness direction. The one-dimensional energy equation for each internal node " $i$ " can be written as follows:

$$
\begin{gathered}
\rho_{\mathrm{p}} C_{\mathrm{p}} d x A_{\mathrm{w}} \frac{d T_{\mathrm{p}, i}}{d t}=h_{\mathrm{w}-\mathrm{p}}\left(T_{\mathrm{w}}-T_{\mathrm{p}, i}\right) A_{\mathrm{w}}-\frac{k_{\mathrm{p}}}{d x}\left(T_{\mathrm{p}, i}-T_{\mathrm{p}, i+1}\right) A_{\mathrm{w}} \\
\quad i=1, \\
\rho_{\mathrm{p}} C_{\mathrm{p}} d x A_{\mathrm{w}} \frac{d T_{\mathrm{p}, i}}{d t}=\frac{k_{\mathrm{p}}}{d x}\left(T_{\mathrm{p}, i-1}-T_{\mathrm{p}, i}\right) A_{\mathrm{w}}-\frac{k_{\mathrm{p}}}{d x}\left(T_{\mathrm{p}, i}-T_{\mathrm{p}, i+1}\right) A_{\mathrm{w}} \\
\quad i=2,3, \ldots, n-1, \\
\rho_{\mathrm{eff}} C_{\mathrm{eff}} d x A_{\mathrm{w}} \frac{d T_{\mathrm{p} . i}}{d t}=\frac{\kappa_{\mathrm{eff}}}{d x}\left(T_{\mathrm{p} . i-1}-T_{\mathrm{p} . i}\right) A_{\mathrm{w}}-U_{\mathrm{ins}}\left(T_{\mathrm{p} . i}-T_{\mathrm{amb}}\right) A_{\mathrm{w}} \\
\quad i=n, \\
\rho_{\mathrm{p}} C_{\mathrm{p}} d x A_{\mathrm{w}} \frac{d T_{\mathrm{p}, i}}{d t}=\frac{k_{\mathrm{p}}}{d x}\left(T_{\mathrm{p}, i-1}-T_{\mathrm{p}, i}\right) A_{\mathrm{w}}-U_{\mathrm{b}}\left(T_{\mathrm{p}, i}-T_{\mathrm{amb}}\right) A_{\mathrm{w}}
\end{gathered}
$$

The heat transfer between different components of this system is shown in Figure 1, where $q_{\mathrm{s}}$ is the solar radiation intensity.

(1) The thermal storage capacity of the PCM

$$
q_{\mathrm{x}}=q_{\mathrm{w}-\mathrm{p}}-q_{\mathrm{b}}
$$

(2) The radiative heat transfer coefficient between the absorber and glass cover has been obtained from [21]

$$
h_{\mathrm{r}, \mathrm{w}-\mathrm{g}}=\frac{\sigma\left(T_{\mathrm{w}}^{2}+T_{\mathrm{g}}^{2}\right)\left(T_{\mathrm{w}}+T_{\mathrm{g}}\right)}{\xi_{\mathrm{w}}{ }^{-1}+\xi_{\mathrm{g}}{ }^{-1}-1} .
$$

(3) The overall heat loss coefficient from the glass cover to ambient $U_{\mathrm{t}}$ includes the convection caused by wind and radiative heat transfer from glass cover to sky. It can be written as

$$
U_{\mathrm{t}}=h_{\mathrm{r}, \mathrm{g}-\mathrm{sky}}+h_{\text {wind }} \text {. }
$$

The radiative heat transfer coefficient from the glass cover to the sky may be obtained from [21]

$$
h_{\mathrm{r}, \mathrm{g} \text {-sky }}=\frac{\sigma \xi_{\mathrm{g}}\left(T_{\mathrm{g}}+T_{\text {sky }}\right)\left(T_{\mathrm{g}}^{2}+T_{\mathrm{sky}}^{2}\right)\left(T_{\mathrm{g}}-T_{\text {sky }}\right)}{T_{\mathrm{g}}-T_{\mathrm{amb}}} .
$$

The sky temperature $T_{\text {sky }}$ and the convective heat transfer coefficient between the glazing cover and the surrounding air, which is affected by wind speed, can be calculated by $[21,22]$

$$
\begin{aligned}
T_{\text {sky }} & =0.0552 T_{\mathrm{amb}}, \\
h_{\text {wind }} & =2.8+3.0 V_{\text {wind }} .
\end{aligned}
$$

(4) The overall heat transfer coefficient between the PCM and the absorber plate $h_{\mathrm{w}-\mathrm{p}}$ is given by

$$
\begin{aligned}
& h_{\mathrm{w}-\mathrm{p}}=\frac{1}{\delta_{\mathrm{w}} / k_{\mathrm{w}}+d x / 2 k}, \\
& q_{\mathrm{w}-\mathrm{p}}=h_{\mathrm{w}-\mathrm{p}}\left(T_{\mathrm{w}}-T_{\mathrm{p}}\right) .
\end{aligned}
$$

(5) The heat that the PCM transfers to indoor is given by

$$
\begin{aligned}
q_{\mathrm{b}} & =U_{\mathrm{b}}\left(T_{\mathrm{p}}-T_{\mathrm{amb}}\right), \\
U_{\mathrm{b}} & =\frac{1}{1 / h_{\mathrm{i}}+\Delta \mathrm{w}_{1} / k_{\mathrm{w} 1}+\Delta \mathrm{w}_{2} / k_{\mathrm{w} 2}} .
\end{aligned}
$$

2.2. Calculation of the Air Flow Rate during the Night. The discharging period begins when the chimney starts ventilating during the night. The air exchanges heat with the absorber plate as it passes through the air channel and then flows to ambient through the outlet. For various components of the system, the energy balance equations for the discharging period are presented below.

Applying the energy balance concept on the glass cover, absorber plate, and air flow in the air channel, the following equations are yielded:

$$
\begin{aligned}
\rho_{\mathrm{g}} C_{\mathrm{g}} \delta_{\mathrm{g}} A_{\mathrm{g}} \frac{d T_{\mathrm{g}}}{d t}= & h_{\mathrm{r}, \mathrm{w}-\mathrm{g}}\left(T_{\mathrm{w}}-T_{\mathrm{g}}\right) A_{\mathrm{w}}+h_{\mathrm{cv}, \mathrm{a}-\mathrm{g}}\left(T_{\mathrm{a}}-T_{\mathrm{g}}\right) A_{\mathrm{g}} \\
& -U_{\mathrm{t}}\left(T_{\mathrm{g}}-T_{\mathrm{amb}}\right) A_{\mathrm{g}}, \\
\rho_{\mathrm{w}} C_{\mathrm{w}} \delta_{\mathrm{w}} A_{\mathrm{w}} \frac{d T_{\mathrm{w}}}{d t}= & h_{\mathrm{p}-\mathrm{w}}\left(T_{\mathrm{p}}-T_{\mathrm{w}}\right) A_{\mathrm{w}}-h_{\mathrm{r}, \mathrm{w}-\mathrm{g}}\left(T_{\mathrm{w}}-T_{\mathrm{g}}\right) A_{w} \\
& -h_{\mathrm{cv}, \mathrm{w}-\mathrm{a}}\left(T_{\mathrm{w}}-T_{\mathrm{a}}\right) A_{\mathrm{w}}, \\
\rho_{\mathrm{a}} C_{\mathrm{a}} V_{\mathrm{a}} \frac{d T_{\mathrm{a}}}{d t}= & h_{\mathrm{cv}, \mathrm{w}-\mathrm{a}}\left(T_{\mathrm{w}}-T_{\mathrm{a}}\right) A_{\mathrm{w}}-h_{\mathrm{cv}, \mathrm{a}-\mathrm{g}}\left(T_{\mathrm{a}}-T_{\mathrm{g}}\right) A_{\mathrm{g}} \\
& -m C_{\mathrm{a}}\left(T_{\mathrm{out}}-T_{\mathrm{in}}\right) .
\end{aligned}
$$

Assuming that the natural convection of the air occurs between the glazing cover and the absorber plate, the convective heat transfer coefficient $h_{\mathrm{cv}, \mathrm{a}-\mathrm{g}}$ between the glazing cover and the air in the channel can be calculated as follows [23]:

$$
\begin{aligned}
h_{\mathrm{cv}, \mathrm{a}-\mathrm{g}} & =h_{\mathrm{cv}, \mathrm{w}-\mathrm{a}}=\frac{\mathrm{Nu} \lambda_{\mathrm{a}}}{\delta_{\mathrm{a}}}, \\
\mathrm{Nu} & =[0.06-0.017(\beta / 90)] \mathrm{Gr}^{1 / 3},
\end{aligned}
$$

where $\beta$ is the inclination angle of the absorber plate $\left(\beta=90^{\circ}\right.$ in this study) and the Grashof number is

$$
\mathrm{Gr}=\frac{g\left|T_{\mathrm{w}}-T_{\mathrm{g}}\right| \delta_{\mathrm{a}}^{3}}{v^{2} T_{\mathrm{a}}}
$$

It is assumed that the mean air temperature inside the chimney is equal to the average value of the absorber temperature and the glazing cover temperature at the absorber side.

$$
T_{\mathrm{a}}=\frac{T_{\mathrm{w}}+T_{\mathrm{g}}}{2} .
$$


The relationship between inlet air temperature and outlet air temperature can be described as follows [24, 25]:

$$
T_{\mathrm{a}}=\gamma T_{\text {in }}+(1-\gamma) T_{\text {out }},
$$

where $\gamma$, the mean temperature approximation coefficient, was found in the literature to be $0.74[21,22]$ and the inlet air temperature $T_{\text {in }}$ can be regarded as the outdoor air temperature.

The airflow rate as a result of the buoyancy effect can be calculated as follows [26]:

$$
m=\frac{C_{\mathrm{d}} \rho_{\mathrm{a}} A_{\text {out }}}{\sqrt{1+A_{\mathrm{r}}^{2}}} \sqrt{2 g \sin \beta L\left(\frac{T_{\mathrm{a}}}{T_{\mathrm{in}}}-1\right)},
$$

where $C_{\mathrm{d}}$ is found in the literature to be 0.57 [26].

$$
C_{\mathrm{a}}=1007+0.04\left(T_{\mathrm{a}}-300\right) .
$$

During the daytime, the initial state of all the PCM is in its solid phase and the whole system's temperature is assumed to be the same as the ambient temperature. For the night ventilation period, the temperature of each system component and the PCM temperature depend on the final charging conditions. The inlet air temperature is equal to the ambient temperature. The temperatures of $T_{\mathrm{w}}, T_{\mathrm{g}}, T_{\mathrm{p}}$, and $T_{\mathrm{a}}$ as well as the airflow rate are obtained with a program solved in "MATLAB." The air outlet temperature $T_{0}$ can be obtained with the mean air temperature and (14). With the developed code, the performance of the PCM-based solar chimney as well as the heat transfer between various components of the solar chimney has been investigated.

\section{Analysis and Discussion of the Numerical Results}

The input parameters of the proposed system are given in Tables 1 and 2. The ventilation time is scheduled for 19:00-7:00. The monthly average solar radiation at the horizontal in Chongqing, China is close to the total solar radiation of June, and the solar radiation on June 26 approaches to the daily average solar radiation of June. Therefore, the climatic parameters of June 26 in Chongqing obtained from [27] are applied in this study, and the solar radiation intensity is given in Figure 2 .

This paper analyzes the effect of phase change temperature on the ventilation rate of a solar chimney under Chongqing climatic conditions. The PCMs used in this numerical study are myristoyl, dodecylic acid, myristelaidic acid, and palmitic acid, and their corresponding phase change temperatures are $38^{\circ} \mathrm{C}, 44^{\circ} \mathrm{C}, 50^{\circ} \mathrm{C}$, and $63^{\circ} \mathrm{C}$, respectively.

Figure 3 shows the stored energy and ventilation rate for different PCMs. It is seen that the higher the phase change temperature, the lower the energy storage and the ventilation rate per unit area of absorber. That is to say, the PCM with phase change temperature of $38^{\circ} \mathrm{C}$ has the best performance among the studied PCMs, while the PCM with phase change temperature of $63^{\circ} \mathrm{C}$ has the poorest performance. Specifically, for the PCM with phase
TABle 1: Specifications of the solar chimney and the thermophysical properties of PCM.

\begin{tabular}{lc}
\hline Cover & \\
\hline Material & Glass \\
Dimension & $1500 \times 1000 \times 8 \mathrm{~mm}$ \\
Surface coating & 0.90 \\
Absorber & Aluminum \\
Plate & $2 \mathrm{~mm}$ \\
Thickness & 0.94 \\
Surface coating & Myristoyl \\
& Dodecylic acid \\
PCMs & Myristelaidic acid \\
& Palmitic acid \\
Melting temperature & $38^{\circ} \mathrm{C}, 44^{\circ} \mathrm{C}, 50^{\circ} \mathrm{C}, 63^{\circ} \mathrm{C}$ \\
Thickness of PCM & $40 \mathrm{~mm}$ \\
Gap & \\
Absorber plate to glass & $200 \mathrm{~mm}$ \\
Insulation material & \\
Extruded insulation panels & $30 \mathrm{~mm}$ \\
\hline
\end{tabular}

change temperature of $38^{\circ} \mathrm{C}$, the solar chimney achieves the maximum energy storage of $4750 \mathrm{~kJ} / \mathrm{m}^{2}$ and the maximum ventilation rate of $610 \mathrm{~kg} / \mathrm{m}^{2}$. However, for the PCM with phase change temperature of $63^{\circ} \mathrm{C}$, there is little energy stored in PCM, and consequently the airflow is not observed during 19:00-07:00.

Figure 4 shows the absorber temperature and the PCM temperature for four different PCMs when storing heat during daytime. As shown, the thermal behavior characteristics of PCM under the identical conditions are different. The temperature variations of PCM display a typical fully charging process for phase change temperatures of $38^{\circ} \mathrm{C}$ and $44^{\circ} \mathrm{C}$, respectively. The melting times for these two PCMs are 5 and $7.5 \mathrm{~h}$, respectively. However, for the phase change temperatures of 50 and $63^{\circ} \mathrm{C}$, the maximum PCM temperatures is $49.6^{\circ} \mathrm{C}$ and $53^{\circ} \mathrm{C}$ at the end of charging process accordingly, indicating that PCMs are not fully melting. Especially for phase change temperature of $63^{\circ} \mathrm{C}$, the PCM temperature even decreases after the peak solar radiation intensity. This is because the absorber surface temperature descends quickly with solar radiation intensity weakens due to the high surface temperature. Consequently, the sensible heat stored in PCM transfers to the absorber surface.

This indicates that a lower phase change temperature can increase the chargeability and dischargeability of the solar chimney. The larger amount of energy stored and discharged by the solar chimney and consequently a higher ventilation rate is achieved. A higher phase change temperature demands higher solar radiation intensity and longer charging time and results in poor chargeability of the chimney.

Figures 5-7 show the variations of air temperature and the transient ventilation rate with time.

It can be seen from Figures 5-7 that the changing trend of ventilation rate is similar to that of the air temperature 
TABLE 2: Initial conditions for numerical modelling.

\begin{tabular}{|c|c|c|c|c|c|}
\hline Item & Value & Item & Value & Item & Value \\
\hline$\alpha_{\mathrm{g}}$ & 0.06 & $K_{\mathrm{w} 2}, \mathrm{Wm}^{-1} \mathrm{~K}^{-1}$ & 0.028 & $v, \mathrm{~m}^{2} \mathrm{~s}^{-1}$ & $19.5 \times 10^{-6}$ \\
\hline$\alpha_{\mathrm{w}}$ & 0.94 & $\rho_{\mathrm{g}}, \mathrm{kgm}^{-3}$ & 2526 & $U_{\mathrm{w}}, \mathrm{Wm}^{-2} \mathrm{~K}^{-1}$ & 26 \\
\hline$\tau_{\mathrm{g}}$ & 0.84 & $\rho_{\mathrm{w}}, \mathrm{kgm}^{-3}$ & 2730 & $h_{\mathrm{i}}, \mathrm{Wm}^{-2} \mathrm{~K}^{-1}$ & 4.55 \\
\hline$\sigma, \mathrm{Wm}^{-2} \mathrm{~K}^{-4}$ & $5.67 \times 10^{-8}$ & $\rho_{\mathrm{p}}, \mathrm{kgm}^{-3}$ & 1007 & $A_{\text {out }}, \mathrm{m}^{2}$ & 0.2 \\
\hline$\lambda_{\mathrm{a}}$ & 0.028 & $C_{\mathrm{g}}, \mathrm{Jkg}^{-1} \mathrm{~K}^{-1}$ & 837 & $A_{\text {in }}, \mathrm{m}^{2}$ & 0.2 \\
\hline$\delta_{\mathrm{a}}, \mathrm{m}$ & 0.3 & $C_{\mathrm{w}}, \mathrm{Jkg}^{-1} \mathrm{~K}^{-1}$ & 880 & $v_{\mathrm{m}}, \mathrm{m}^{2} \mathrm{~s}^{-1}$ & $17.5 \times 10^{-6}$ \\
\hline$\Delta \mathrm{w}_{1}, \mathrm{~m}$ & 0.3 & $V_{\mathrm{g}}, \mathrm{m}^{3}$ & 0.012 & Pr & 0.7 \\
\hline$\Delta \mathrm{w}_{2}, \mathrm{~m}$ & 0.03 & $V_{\mathrm{w}}, \mathrm{m}^{3}$ & 0.003 & C & 0.57 \\
\hline
\end{tabular}

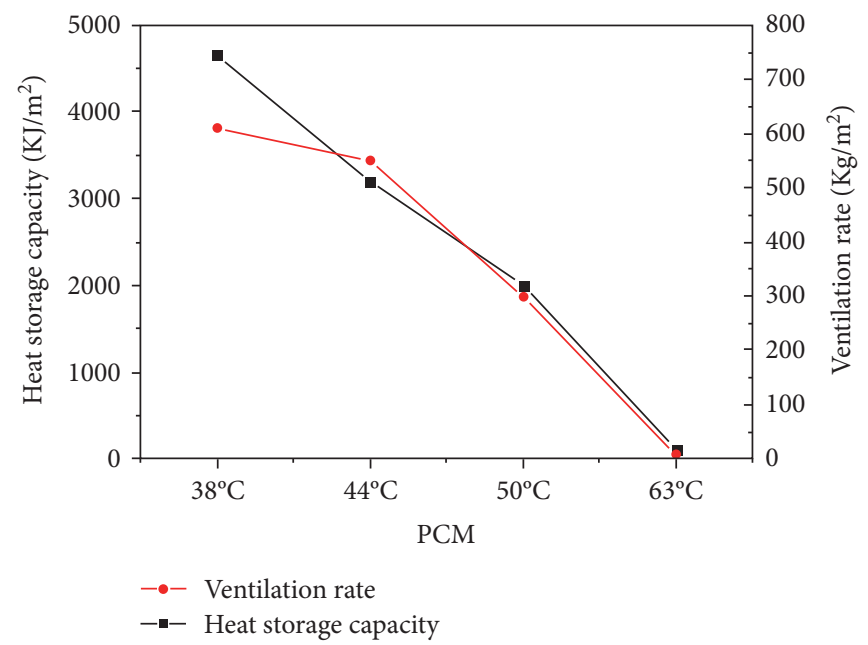

FIgure 3: Thermal storage capacity and air flow rate for four different PCMs.

difference between inlet and outlet. Higher phase change temperature leads to poor chargeability of the chimney and has the shorter ventilation time. The ventilation times corresponding to different PCMs are shown in Table 3.

As shown in Table 3, when the phase change temperature of the PCM is $38^{\circ} \mathrm{C}$, the longest ventilation time of 12 hours was achieved while the PCM with phase change temperature of $50^{\circ} \mathrm{C}$ has the shortest ventilation time which is only 4.33 hours. This is because more solar energy was stored in the PCM with lower phase change temperature.

Figures 8 and 9 show the energy storage and release of different components of chimney combined with the dodecylic acid (phase change temperature of $44^{\circ} \mathrm{C}$ ) during the day and night, respectively.

It can be seen from Figure 8 that the available solar energy $Q_{\mathrm{s}}$ is as high as $11,000 \mathrm{~kJ} / \mathrm{m}^{2}$, while the energy stored in $P C M Q_{x}$ is only $3150 \mathrm{~kJ} / \mathrm{m}^{2}$, which accounts for $28.6 \%$ of the $Q_{s}$. The heat transferred by radiation from glass cover to ambient $Q_{\mathrm{g} \text {-amb }}$ is $5090 \mathrm{~kJ} / \mathrm{m}^{2}$ that accounts for $46.3 \%$ of $Q_{s}$. It means that nearly $50 \%$ of the solar energy is lost through glass cover to ambient during the daytime period. The solar energy utility efficiency is still low for PCM of dodecylic acid.

It can be seen from Figure 9 that most of energy stored in PCM is transferred to absorber surface, $Q_{\mathrm{p}-\mathrm{w}}$ accounts for
$89 \%$ of $Q_{\mathrm{x}}$. However, $80 \%$ of $Q_{\mathrm{p}-\mathrm{w}}$ loses to ambient through glass cover during night ventilation. The heat absorbed by air $Q_{a}$ is only about $13 \%$ of $Q_{x}$. This means that most of heat stored in PCM is lost to ambient through glass cover by radiation during the night ventilation; only a small portion is used for heating the air within air channel.

\section{Validation of the Numerical Model}

The numerical model is validated by comparing numerical predictions of PCM temperature and air mass flow rate with the experimental results obtained from Liu and Li's study [28]. This experiment investigated the thermal performance of a solar chimney integrated with PCM for a given heat flux. The PCM temperature during charging and discharging processes and air flow rate were investigated. As shown in Figure 10, a rectangular PCM container with dimensions of $1000 \mathrm{~mm}$ wide $\times 1600 \mathrm{~mm}$ high $\times 40 \mathrm{~mm}$ deep was constructed of stainless steel. A total of $50 \mathrm{~kg}$ RT42 was used to fill the container, and the physical properties of RT42 was given in [28]. In their experimental testing, the openings of inlet and outlet were closed during the charging period. The discharging period happened right after the charging period. A number of $\mathrm{K}$ type thermocouples with the measurement range of -50 to 


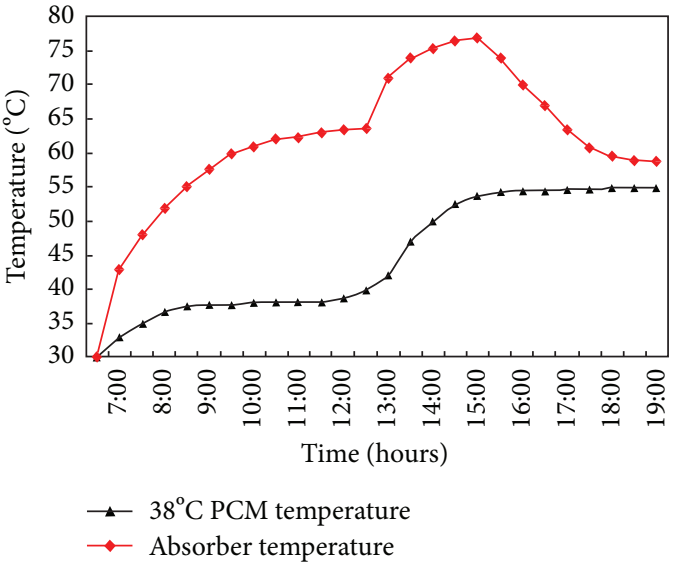

(a)



(c)

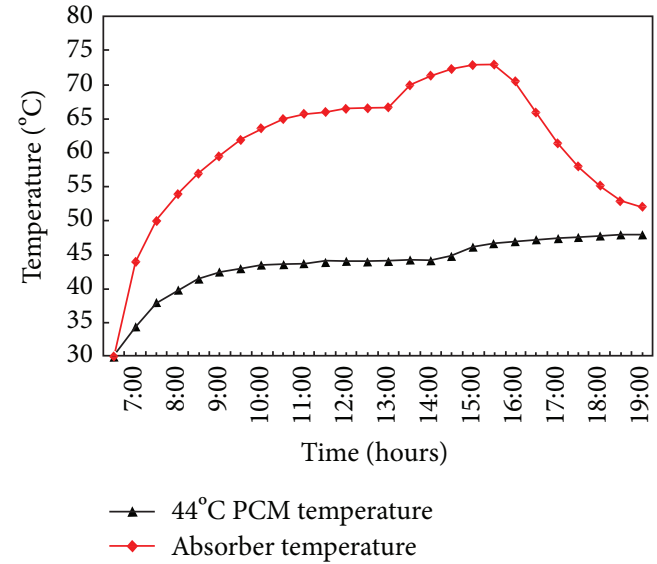

(b)

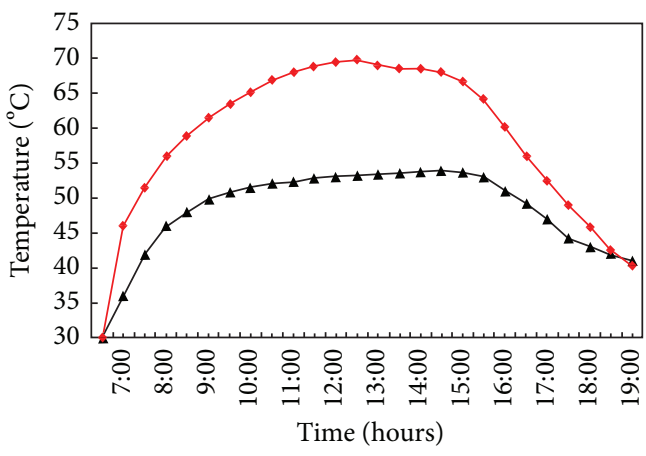

$\rightarrow 63^{\circ} \mathrm{C}$ PCM temperature

- Absorber temperature

(d)

FIgURe 4: Absorber temperature and PCM temperature for four different PCMs when storing heat during the day.

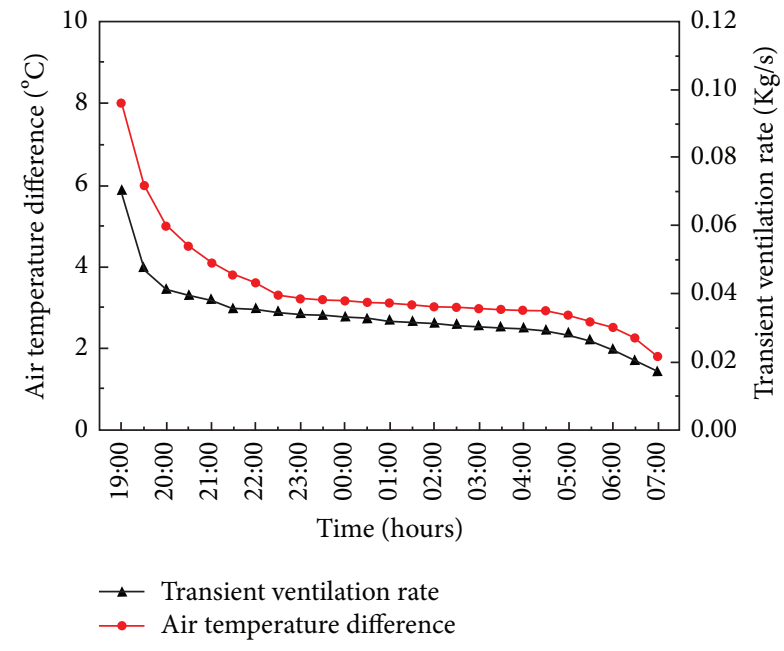

FIGURE 5: Variation of air temperature and ventilation rate for phase change temperature of $38^{\circ} \mathrm{C}$.

$250^{\circ} \mathrm{C}$ and accuracy of $\pm 0.3^{\circ} \mathrm{C}$ were distributed on the glass cover, absorber plate, inside the PCM, and the air channel. Air velocities inside the air channel are measured by a TSI8455 air flow probe with the measurement

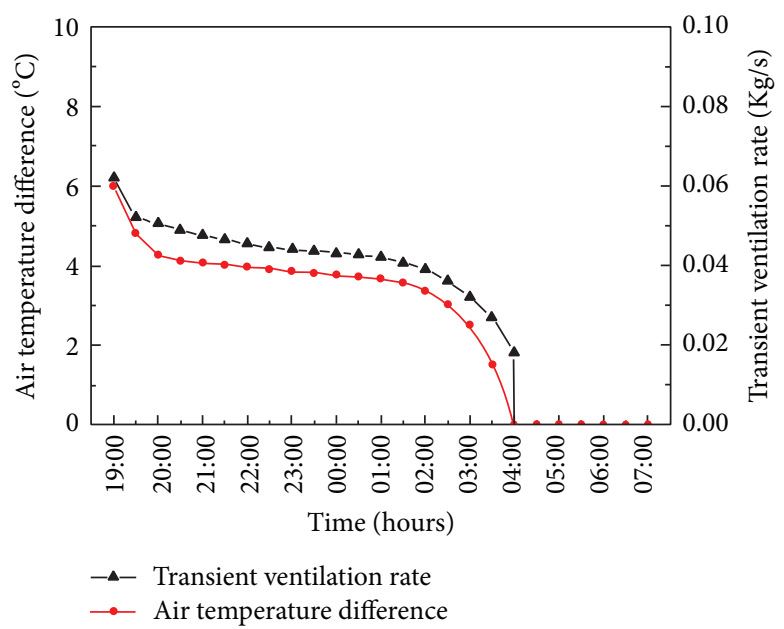

FIGURE 6: Variation of air temperature and ventilation rate for phase change temperature of $44^{\circ} \mathrm{C}$.

range of $0-50 \mathrm{~m} / \mathrm{s}$ and accuracy of $\pm 3 \%$ of reading. The setup of the developed model in this study follows the experimental conditions. Figure 11(a) shows the PCM temperatures obtained by numerical simulation and experiment testing. It can be seen that there was a good 
TABLE 3: Ventilation times corresponding to different PCMs.

\begin{tabular}{lccc}
\hline Type & $\begin{array}{c}\text { Phase change } \\
\text { temperature } \\
\left({ }^{\circ} \mathrm{C}\right)\end{array}$ & $\begin{array}{c}\text { Time } \\
\text { period }\end{array}$ & $\begin{array}{c}\text { Total time } \\
\text { (hour) }\end{array}$ \\
\hline The myristoyl & 38 & $19: 00-7: 00$ & 12 \\
The dodecylic acid & 44 & $19: 00-4: 00$ & 9 \\
The myristelaidic acid & 50 & $19: 00-23: 20$ & 4.33 \\
\hline
\end{tabular}

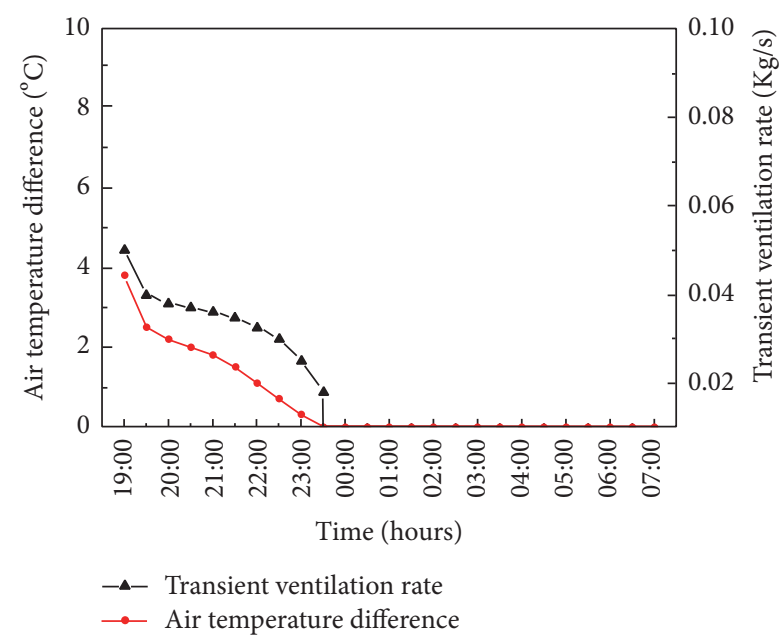

FIGURE 7: Variation of air temperature and ventilation rate for phase change temperature of $50^{\circ} \mathrm{C}$.

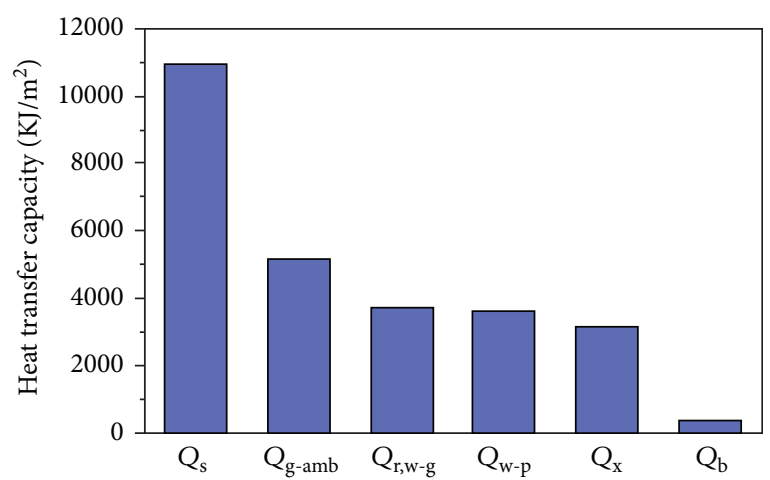

FIGURE 8: Heat transfer between different components of chimney during the day.

agreement between the numerical data and experimental data. The coherence indicates the validity of the developed numerical model. Figure 11(b) shows that the predicted air flow rate varies with the measured one within a small divergence. Therefore, it has the capability to predict the mass flow rate accurately.

\section{Conclusions}

In this present paper, a numerical model is developed for optimizing the phase change temperature for a PCM-based

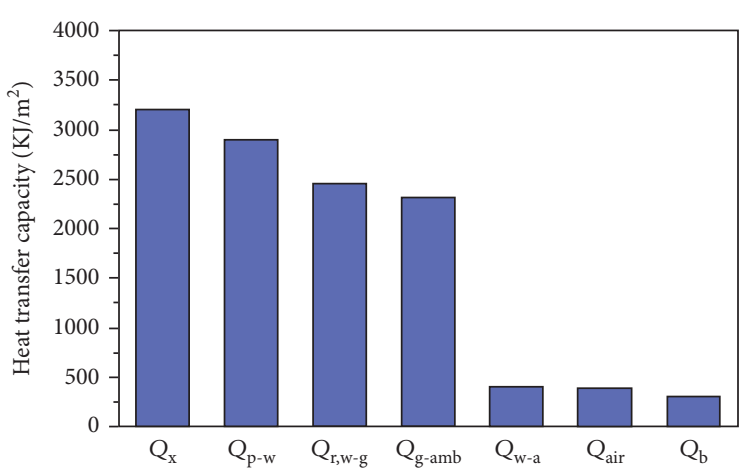

FIgURE 9: Heat transfer between the different components of chimney during the nighttime.

solar chimney by considering the amount of energy stored in PCM and ventilation rate. Based on the numerical results, the following conclusions can be made:

(1) The higher the phase change temperature, the lower the energy storage and ventilation rate per unit area of absorber. In this study, the PCM with phase change temperature of $38^{\circ} \mathrm{C}$ has the best performance among the studied PCMs while the PCM with phase change temperature of $63^{\circ} \mathrm{C}$ has the poorest performance. Specifically, for the PCM with phase change temperature of $38^{\circ} \mathrm{C}$, the solar chimney achieves the maximum energy storage of $4750 \mathrm{~kJ} / \mathrm{m}^{2}$ and the maximum ventilation rate of $610 \mathrm{~kg} / \mathrm{m}^{2}$. However, for PCM with phase change temperature of $63^{\circ} \mathrm{C}$, there is little energy stored in PCM and the ventilation does not occur during the scheduled ventilation time.

(2) A lower phase change temperature can increase the chargeability and dischargeability of the solar chimney. The larger amount of energy stored and discharged by the solar chimney and consequently a higher ventilation rate is achieved. A higher phase change temperature demands higher solar radiation intensity and longer charging time, and results in poor chargeability of the chimney.

(3) During daytime, the energy stored in PCM with phase change temperature of $44^{\circ} \mathrm{C}, Q_{\mathrm{x}}$ only accounts for $28.6 \%$ of the available solar energy, while nearly $50 \%$ of the solar energy is lost through glass cover to ambient by radiation during daytime period. The solar energy utility efficiency is low.

(4) During night ventilation period, the heat absorbed by air $Q_{\mathrm{a}}$ is only about $13 \%$ of $Q_{\mathrm{x}}$. This means that most of the heat stored in PCM is lost to ambient through glass cover by radiation; only a small portion is used for heating the air within air channel.

(5) It can be concluded that most of the stored energy is lost through glass cover to ambient by radiant heat transfer. Therefore, reducing the radiation heat transfer coefficient of glass cover can increase the night ventilation effectively. 

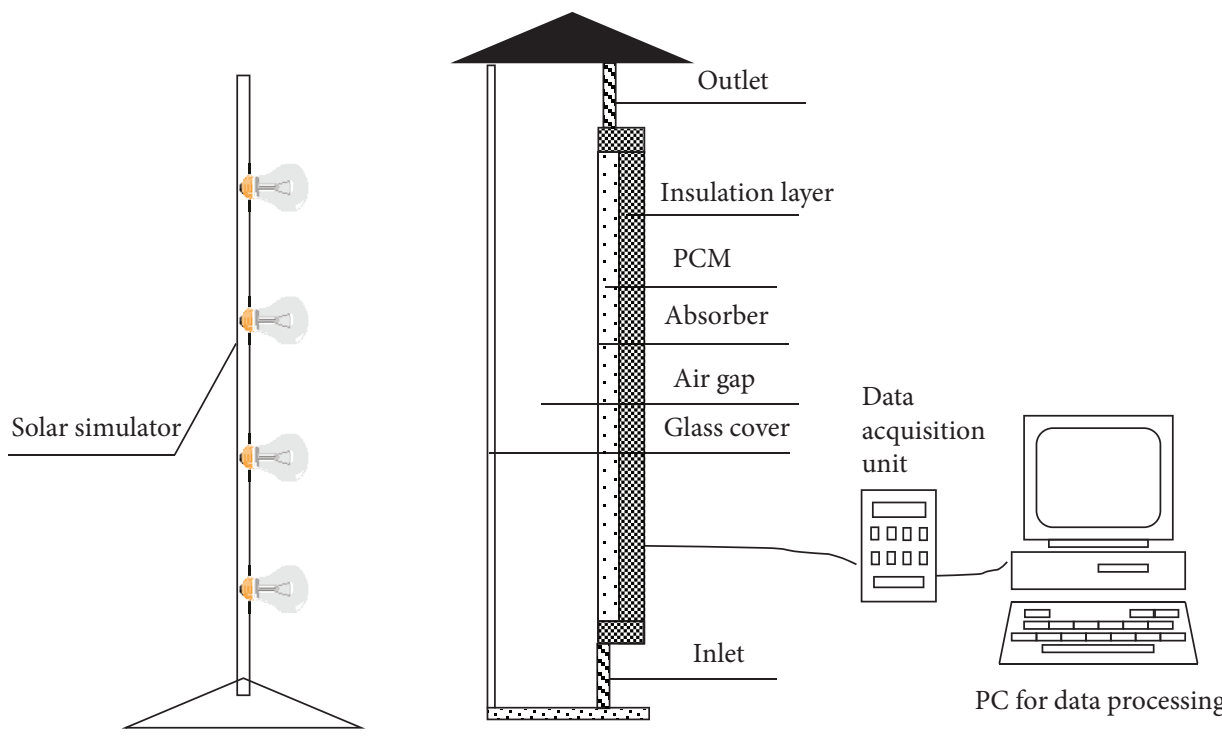

Figure 10: The schematic diagram of the experimental solar chimney.

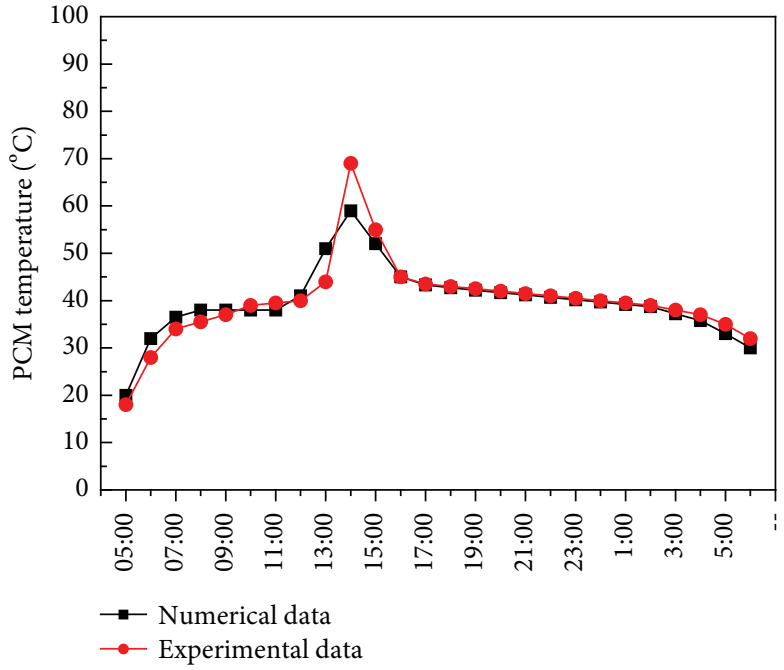

(a)

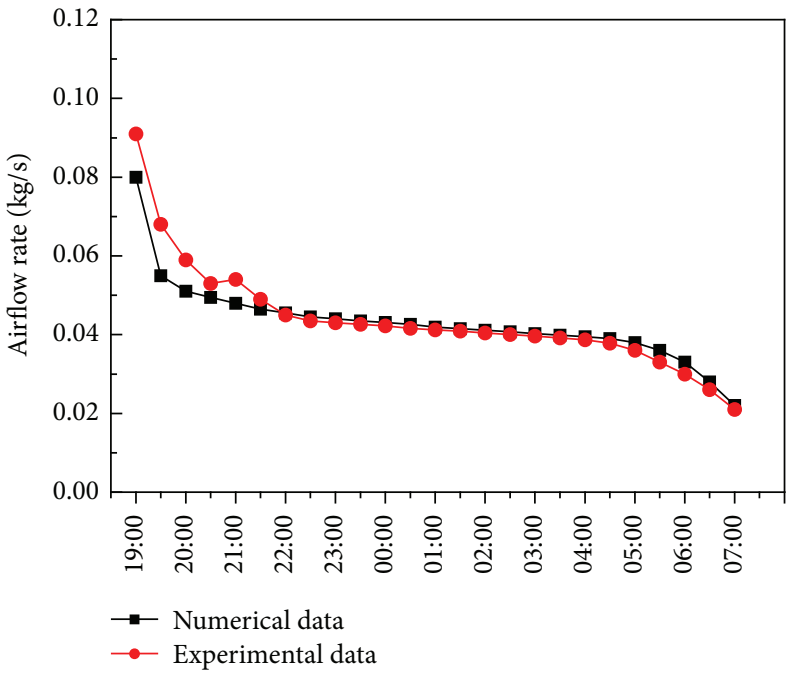

(b)

FIGURE 11: Comparison of numerical and experimental results: (a) absorber temperature and (b) airflow rate.

\section{Nomenclature}

A: $\quad$ Surface area $\left(\mathrm{m}^{2}\right)$

$A_{\text {in }}, A_{\text {out }}:$ Cross sectional area of inlet and outlet $\left(\mathrm{m}^{2}\right)$

$A_{\mathrm{r}}: \quad$ Aspect ratio of $A_{\text {in }} / A_{\text {out }}$

$C_{\mathrm{d}}: \quad$ Coefficient of discharge of air channel inlet

C: $\quad$ Specific heat $\left(\mathrm{J} \cdot \mathrm{kg}^{-1} \mathrm{~K}^{-1}\right)$

$h$ : $\quad$ Convective heat transfer coefficient

$K_{\mathrm{w} 1}: \quad$ Thermal conductivity of brick wall $\left(\mathrm{W} \cdot \mathrm{m}^{-1} \mathrm{~K}^{-1}\right)$

$K_{\mathrm{w} 2}$ : Thermal conductivity of extruded insulation panels $\left(\mathrm{W} \cdot \mathrm{m}^{-1} \mathrm{~K}^{-1}\right)$

$L: \quad$ Length $(\mathrm{m})$

$m: \quad$ Mass flow rate $\left(\mathrm{kg} \cdot \mathrm{s}^{-1}\right)$

Q: $\quad$ Total heat $(\mathrm{kJ})$ $q: \quad$ Heat transfer $(\mathrm{W})$

$q_{s}: \quad$ Solar radiation intensity $\left(\mathrm{W} \cdot \mathrm{m}^{-2}\right)$

T: $\quad$ Temperature $(\mathrm{K})$

$U_{\mathrm{b}}$ : Overall heat transfer coefficient from PCM to indoor $\left(\mathrm{W} \cdot \mathrm{m}^{-2} \mathrm{~K}^{-1}\right)$

$U_{\mathrm{t}}: \quad$ Overall heat transfer coefficient from glass cover to ambient $\left(\mathrm{W} \cdot \mathrm{m}^{-2} \mathrm{~K}^{-1}\right)$

$V: \quad$ Volume $\left(\mathrm{m}^{3}\right)$

$v: \quad \operatorname{Velocity}\left(\mathrm{m} \cdot \mathrm{s}^{-1}\right)$

\section{Greek Symbols}

$\Delta \mathrm{w}_{1}$ : Thickness of brick wall

$\Delta \mathrm{w}_{2}$ : Thickness of extruded insulation panels 


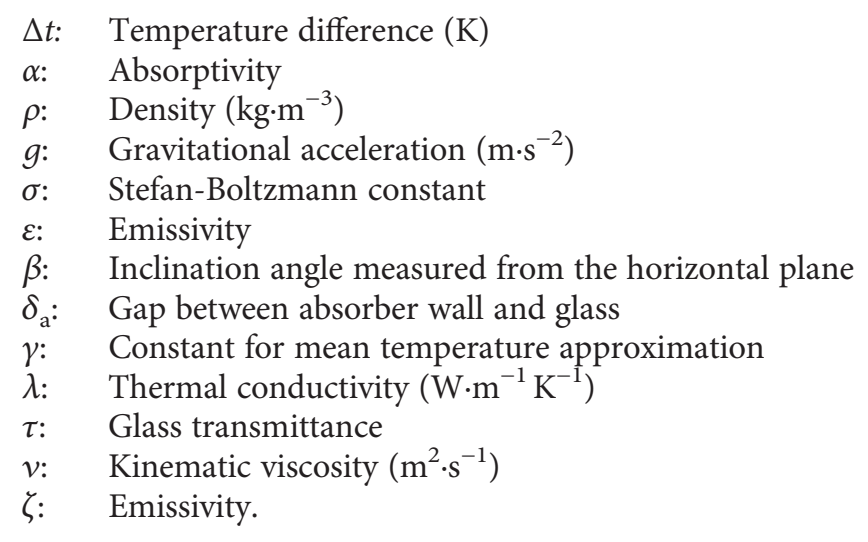

\section{Subscripts}

amb: Ambient conditions

a: $\quad$ Air in the air flow channel

a-g: $\quad$ From air to glass

b: $\quad$ From PCM to indoor

c: Chimney

$\mathrm{cv}, \mathrm{w}-\mathrm{a}$ : Convective from black wall to air

cv,a-g: Convective from air to glass

in: Inlet

out: Outlet

g: $\quad$ Glass

g-sky: From glass to sky

i: $\quad$ From PCM to indoor

p: $\quad$ PCM

p-w: From PCM to black wall

r: Room

r,g-sky: Radiative from glass to sky

r,w-g: Radiative from black wall to glass

s: $\quad$ Sky

t: Air flow channel of the solar roof

w: Absorber wall

w-a: From absorber wall to air

w-g: $\quad$ From absorber wall to the glass

w-p: From absorber wall to PCM

$\mathrm{x}$ : $\quad$ Storage capacity of the PCM.

\section{Dimensionless Terms}

Nu: Nusselt number

Pr: Prandtl number

Ra: Rayleigh number

Gr: Grashof number.

\section{Conflicts of Interest}

The authors declare no conflict of interests regarding the publication of this paper.

\section{Acknowledgments}

The authors gratefully acknowledge the support from the National Science Foundation of China (no. 51478058), the 111 Project (no. B13041), and the Fundamental Research Funds for the Central Universities (no. 106112015CDJXY210006).

\section{References}

[1] J. DeBlois, M. Bilec, and L. Schaefer, "Simulating home cooling load reductions for a novel opaque roof solar chimney configuration," Applied Energy, vol. 112, no. 4, pp. 142-151, 2013.

[2] M. Maerefat and A. P. Haghighi, "Natural cooling of standalone houses using solar chimney and evaporative cooling cavity," Renewable Energy, vol. 35, no. 9, pp. 2040-2052, 2010.

[3] W. P. Puangsombut, J. Hirunlabh, J. Khedari, B. Zeghmati, and M. M. Win, "Enhancement of natural ventilation rate and attic heat gain reduction of roof solar collector using radiant barrier," Building and Environment, vol. 42, no. 6, pp. 2218 2226, 2007.

[4] L. Susanti, H. Homma, and H. Matsumoto, "A naturally ventilated cavity roof as potential benefits for improving thermal environment and cooling load of a factory building," Energy and Buildings, vol. 43, no. 1, pp. 211-218, 2011.

[5] J. DeBlois, M. Bilec, and L. Schaefer, "Simulating home cooling load reductions for a novel opaque roof solar chimney configuration," Applied Energy, vol. 112, no. 12, pp. 142-151, 2013.

[6] H. W. Jing, Z. D. Chen, and A. G. Li, "Experimental study of the prediction of the ventilation flow rate through solar chimney with large gap-to-height ratios," Building and Environment, vol. 89, pp. 150-159, 2015.

[7] A. Y. K. Tan and N. H. Wong, "Natural ventilation performance of classroom with solar chimney system," Energy and Buildings, vol. 53, no. 53, pp. 19-27, 2012.

[8] D. S. Lee, T. C. Hung, J. R. Lin, and J. Zhao, "Experimental investigations on solar chimney for optimal heat collection to be utilized in organic Rankine cycle," Applied Energy, vol. 154, no. 53, pp. 651-662, 2015.

[9] R. Bassiouny and N. S. A. Korah, "Effect of solar chimney inclination angle on space flow pattern and ventilation rate," Energy and Buildings, vol. 41, no. 2, pp. 190-196, 2009.

[10] H. H. Al-Kayiem, K. V. Sreejaya, and S. I. U. H. Gilani, "Mathematical analysis of the influence of the chimney height and collector area on the performance of a roof top solar chimney," Energy and Buildings, vol. 68, no. 1, pp. 305-311, 2014.

[11] J. Khedari, B. Boonsri, and J. Hirunlabh, "Ventilation impact of a solar chimney on indoor temperature fluctuation and air change in a school building," Energy and Buildings, vol. 32, no. 1, pp. 89-93, 2000.

[12] J. Hirunlabh, S. Wachirapuwadon, N. Pratinthong, and J. Khedari, "New configurations of a roof solar collector maximizing natural ventilation," Building and Environment, vol. 36, no. 3, pp. 383-391, 2001.

[13] S. Chungloo and B. Limmeechokchai, "Application of passive cooling systems in the hot and humid climate: the case study of solar chimney and wetted roof in Thailand," Building and Environment, vol. 42, no. 9, pp. 3341-3351, 2007.

[14] T. Miyazaki, A. Akisawa, and T. Kashiwagi, "The effects of solar chimneys on thermal load mitigation of office buildings under the Japanese climate," Renewable Energy, vol. 31, no. 7, pp. 987-1010, 2006.

[15] A. A. Imran, J. M. Jalil, and S. T. Ahmed, "Induced flow for ventilation and cooling by a solar chimney," Renewable Energy, vol. 78, no. 12, pp. 236-244, 2015.

[16] N. Saifi, N. Settou, B. Dokkar, B. Negrou, and N. Chennouf, "Experimental study and simulation of airflow in solar chimneys,” Energy Procedia, vol. 18, no. 4, pp. 1289-1298, 2012. 
[17] J. Arce, M. J. Jimenez, J. D. Guaman, M. R. Heras, G. Alvarez, and J. Xaman, "Experimental study for natural ventilation on a solar chimney," Renewable Energy, vol. 34, no. 12, pp. 2928-2934, 2009.

[18] K. E. Amori and S. W. Mohammed, "Experimental and numerical studies of solar chimney for natural ventilation in Iraq," Energy and Buildings, vol. 47, no. 4, pp. 450-457, 2012.

[19] S. Liu and Y. Li, "An experimental study on the thermal performance of a solar chimney without and with PCM," Renewable Energy, vol. 81, pp. 338-346, 2015.

[20] G. Zhou and M. Pang, "Experimental investigations on the performance of a collector-storage wall system using phase change materials," Energy Conversion and Management, vol. 105, pp. 178-188, 2015.

[21] K. S. Ong, "A mathematical model of a solar chimney," Renewable Energy, vol. 28, no. 7, pp. 1047-1060, 2003.

[22] K. S. Ong and C. C. Chow, "Performance of a solar chimney," Solar Energy, vol. 74, no. 1, pp. 1-17, 2003.

[23] A. P. Haghighi and M. Maerefat, "Solar ventilation and heating of buildings in sunny winter days using solar chimney," Sustainable Cities \& Society, vol. 10, pp. 72-79, 2014.

[24] R. Bassiouny and N. S. A. Koura, "An analytical and numerical study of solar chimney use for room natural ventilation," Energy and Buildings, vol. 40, no. 5, pp. 865-873, 2008.

[25] N. K. Bansal, J. Mathur, S. Mathur, and M. Jain, "Modeling of window-sized solar chimneys for ventilation," Building and Environment, vol. 40, no. 10, pp. 1302-1308, 2005.

[26] R. Bassiouny and N. S. A. Korah, "Effect of solar chimney inclination angle on space flow pattern and ventilation rate," Energy and Buildings, vol. 41, no. 2, pp. 190-196, 2009.

[27] China Meteorological Administration, Tsinghua University, Weather Data for Built Environment Thermal Analysis of China, China Architecture \& Building Press, Beijing, 2005.

[28] Y. Li and S. Liu, "Experimental study on thermal performance of a solar chimney combined with PCM," Applied Energy, vol. 114, pp. 172-178, 2014. 

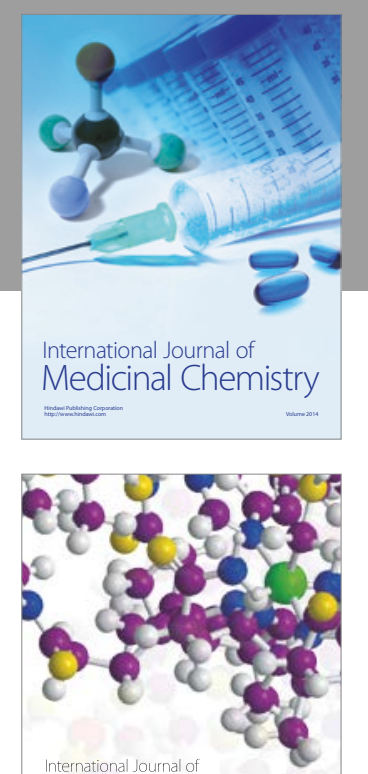

Carbohydrate Chemistry



The Scientific World Journal
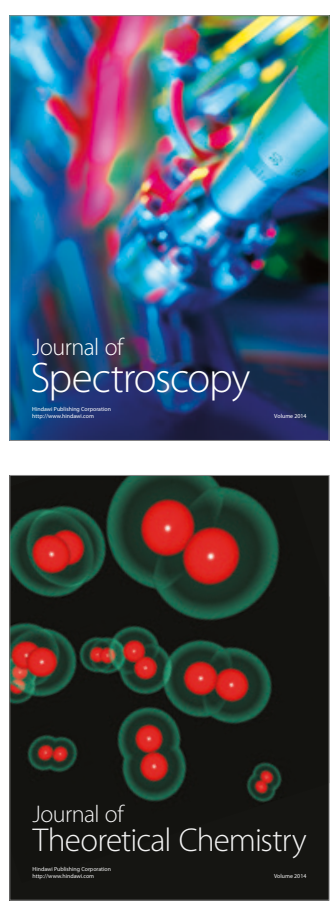
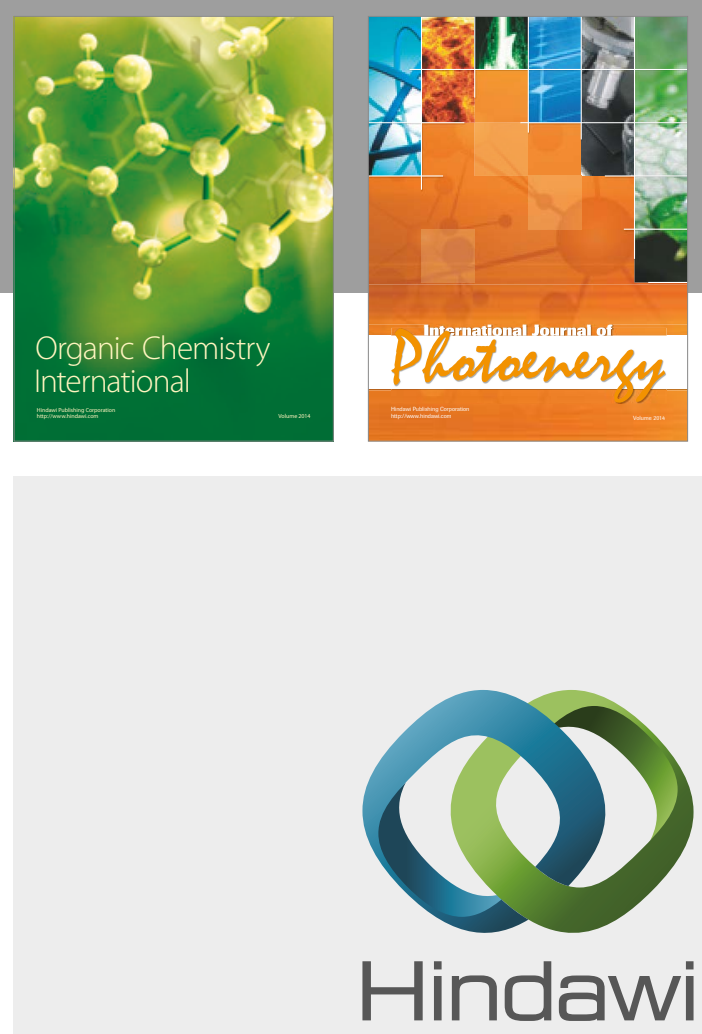

Submit your manuscripts at

https://www.hindawi.com

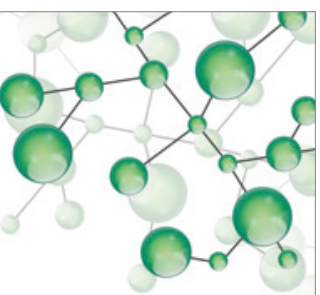

International Journal of

Inorganic Chemistry



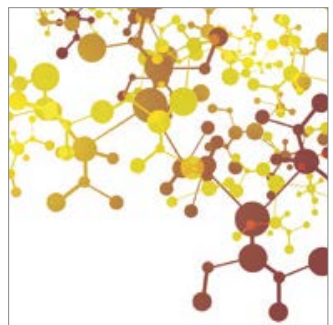

Applied Chemistry
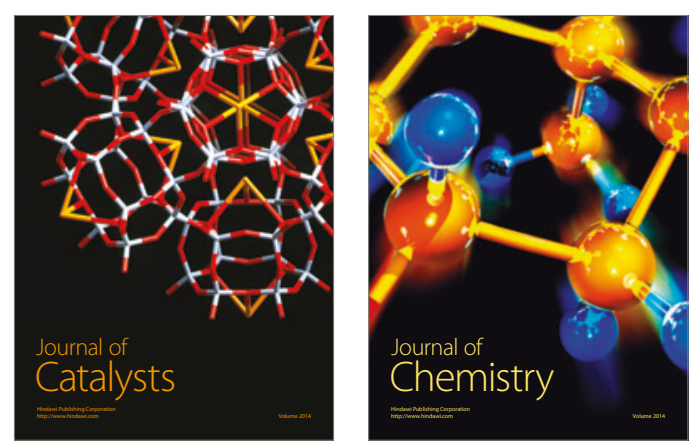
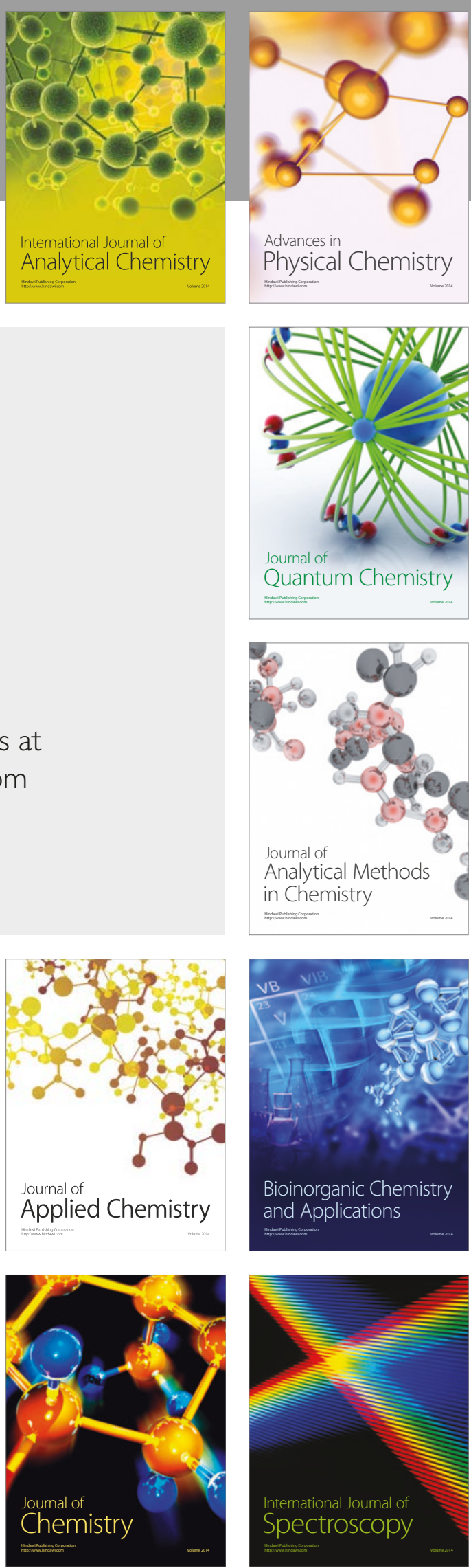